\title{
Post-stroke depression and lesion location: a systematic review
}

\author{
Na Wei $\cdot$ Wu Yong $\cdot$ Xinyan Li $\cdot$ Yafan Zhou \\ Manfei Deng $\cdot$ Houze Zhu $\cdot$ Huijuan Jin
}

Received: 23 September 2014/Revised: 4 October 2014/ Accepted: 6 October 2014/Published online: 12 October 2014

(C) Springer-Verlag Berlin Heidelberg 2014

\begin{abstract}
Post-stroke depression (PSD) is a frequent problem in stroke rehabilitation. Several studies have evaluated association between the lesion location and the risk of depression. Different conclusions and contradictory findings have been published. The aim of the present study was to perform a systematic meta-analysis to evaluate the relationship between PSD and lesion location. We researched PubMed, ISI Web of Science, EMBASE, and systematically reviewed available publications reporting investigations on stroke location and risk of PSD. Subgroup analyses were performed according to the time since stroke onset to assessment for PSD or the source of patients. Odds ratios (ORs) and $95 \%$ confidence intervals (CIs) were used for pooled analyses. Heterogeneity was assessed with Cochran's $Q$ test and $I^{2}$ test. Begg's funnel plot and Egger's test were used to examine the publication bias. A total of 43 studies involving 5,507 patients suffering from stroke were included in this meta-analysis. The pooled OR with $95 \%$ CI for the overall association of stroke location and depression risk was 0.99 (0.88-1.11). Subgroups analyses highlighted that only studies with subacute post-stroke group (1-6 months) showed a
\end{abstract}

N. Wei and W. Yong contributed equally to this work.

Electronic supplementary material The online version of this article (doi:10.1007/s00415-014-7534-1) contains supplementary material, which is available to authorized users.

N. Wei $\cdot$ X. Li $\cdot$ Y. Zhou $\cdot$ M. Deng $\cdot$ H. Zhu $\cdot$ H. Jin $(\bowtie)$ Institute of Brain Research, Huazhong University of Science and Technology, Wuhan 430030, China

e-mail: jinhuijuan1983@163.com

W. Yong

Institute of Psychology, Chinese Academy of Sciences,

Beijing 100015, China statistical association between right hemisphere stroke and risk of depression (OR $=0.79,95 \%$ CI 0.66-0.93). This systematic review offered no support for the hypothesis that lesion of the left hemisphere was associated with an increased risk of depression after stroke. We only find significant association between right hemisphere stroke and incidence of depression for studies within subacute poststroke phase.

Keywords Post-stroke depression - Lesion location . Meta-analysis

\section{Introduction}

Post-stroke depression (PSD) is of high clinical importance. Patients with PSD have more functional disability [1], poorer rehabilitation outcomes [2], and increased morbidity, and mortality in the first year after stroke onset [3]. Depression is often persistent after stroke, with high risk of relapse even after remission over a long period of time [4]. Reported prevalence of PSD varies widely, ranging from 25 to $79 \%$. Recently, a systematic review of observational studies indicated that depressive symptoms were present in approximately $33 \%$ of all stroke survivors [5].

Although many studies of PSD have been reported, clinical association between the lesion location and the occurrence of depression remains a matter of debate. The possibility that the risk of depression after stroke is related to lesion location was developed more than 40 years ago at John Hopkins University and originated the concept of PSD [6]. Then, the same group's pooling results underlined that left hemisphere strokes may be associated with higher incidence of depression, especially the left anterior cerebral 
lesions [7-9]. In contrast, some studies suggest the opposite results [10]. The attempts to systematically review studies of lesion location and PSD also have not served to clarify this association. Two meta-analyses did not support the hypothesis that the risk of PSD is due to a specific location of stroke [11, 12]. A systematic review by Bhogal et al. [13] sustained that depression was related to the left hemispheric stroke, while Yu et al. [14] suggest that there was a weak relationship between PSD and right hemisphere lesion. The lack of uniformity in definition and measurement of depression, highly variable time since stroke onset to assessment for PSD, sampling differences, and different study settings may partly explain these discrepancies.

In this article we not only expand the related literatures and explore the heterogeneity that might exist among results, but also rejudge and exclude some literatures that included in previous reviews, such as the studies with duplicate data, and studies that were not nonstandard for diagnosis of depression, especially studies that misdiagnosed depressive mood as depression. The major object is to investigate the relationship between stroke lesion location and the development of depression more precisely and completely.

\section{Methods}

\section{Searching strategy}

All studies that included an assessment of depression in patients who had stroke and examined the correlation between PSD and lesion location were initially eligible for inclusion.

Potential studies were identified by a comprehensive electronic search updated to 5 January 2014, via databases of PubMed, ISI Web of Science, and EMBASE. Our strategy used the keywords:

((stroke[MeSH Terms]) OR post-stroke[Title/Abstract]) OR post stroke[Title/Abstract])) AND (((depressive disorder[MeSH Terms]) OR depression[MeSH Terms]) OR mood disorders[MeSH Terms]).

\section{Study selection}

The inclusion criteria required: (1) the studies must have examined the association between depression after stroke and lesion location; (2) they must have provided information sufficient for the computation of effect sizes; (3) studies defining depression as a diagnosis made using DSM-IV criteria, a score above a cut-off point in a validated scale, or another validated method of diagnosis; (4) imaging using either CT or MR scanning; (5) the search was restricted to studies published in English and involving human subjects.

Studies were excluded if they had any of the following: (1) studies limited to specific clinical characteristics (e.g., strokes in specific locations, strokes of a specific subtype); (2) they were limited to specific patient characteristics (e.g., patients of a specific age group); (3) studies of mixed populations (e.g., stroke and head injury) unless separate results for stroke patients were identified; (4) duplicate studies were excluded. These were defined as studies that shared a sampling frame, and had overlapping study dates, and similar or identical reported sample characteristics. Among duplicate studies, the study that gave original data on the largest number of participants was selected. If the studies were conducted on the same number of participants, the earliest one was used; (5) abstracts, review articles, case reports, retrospective recruitment studies or pharmacological intervention studies were excluded.

\section{Data collection and extraction}

Two investigators (Wei $\mathrm{N}$ and Zhou $\mathrm{Y}$ ) independently extracted the estimates on the basis of the inclusion and exclusion criteria. Disagreements were resolved by a group discussion, after which the primary investigators made the final decision. We extracted the following information from each included study: (1) first author, (2) year of publication, (3) demographic characteristics, (4) depression definitions and measures, (5) sample size, (6) the timing of interview for depression, (7) lesion localization, (8) exclude/include aphasia patients, (9) history of stroke or depression, (10) final conclusions. If a report did not include the data needed for the meta-analysis, the corresponding author was contacted in an effort to gather any required information not reported.

\section{Assessment of quality of studies}

The quality of included studies was evaluated independently by two investigators ( $\mathrm{Li} \mathrm{X}$ and Deng $\mathrm{M}$ ) according to the Newcastle-Ottawa scale (NOS) (http:// www.ohri.ca/programs/clinical_epidemiology/oxford.asp).

The third reviewer (Wei $\mathrm{N}$ ) examined the results, and a consensus was reached. The NOS uses a 'star' rating system to judge quality based on three aspects of the study: selection, comparability, and exposure (case-control studies) or outcome (cohort studies). Scores were ranged from 0 (worst) to 9 stars (best). We specifically classified studies at low quality (1-3 stars), intermediate quality (4-5 stars), or high quality (6-9 stars). Study with a score equal to or higher than 4 was included in this meta-analysis. 


\section{Statistics analysis}

We used Stata software (version 11.0; College Station, TX, USA) for statistical analysis and to derive forest plots showing the results of individual studies and pooled analysis. Heterogeneity among studies was examined by Cochran's $Q$ test $\left(P_{\text {heterogeneity }}\right)$ and then quantified by $I^{2}$ statistic. If the $P_{\text {heterogeneity }}<0.10$ or $I^{2}>50 \%$, the pooled ORs and $95 \%$ CIs were estimated by a randomeffects model because of significant heterogeneity; otherwise, they were evaluated by a fixed-effects model. Sensitivity analysis was used to assess the stability of results, in which each study was removed at a time and the rest were analyzed to recalculate the pooled OR to evaluate whether the results were affected statistically significantly. Publication bias was evaluated using the Begg's funnel plot and Egger's test $[15,16]$. All $P$ values were two-sided with a significant level at 0.05 expect for Cochran's $Q$ test $\left(P_{\text {heterogeneity }}<0.10\right)$.

To explore the heterogeneity among study results, we conducted analyses in which subgroups were formed according to each study characteristic. The analysis was done in two stages. Firstly, all studies were included and the relationship of PSD and lesion location was calculated. For studies showing results at different follow-up periods, we included just the results at the first follow-up; secondly, we performed subgroups analyses based on the follow-up periods of the included studies: acute post-stroke phase ( $\leq 1$ month), subacute post-stroke phase (1-6 months), and chronic post-stroke phase ( $>6$ months); lastly, we performed subgroups analyses based on the source of patients (clinic, rehabilitation centre, and community).

\section{Results}

Characteristics for studies included

The initial search yielded 1,649 citations. 1,545 citations were initially excluded for not meeting the criteria outlined above, based on information garnered from their abstracts. After screening based on full text, 43 original reports were included in the review [7, 10, 17-57]. The process of the study search and detailed reasons for ineligibility are depicted in Fig. 1. The study characteristics and demographics are displayed in Table 1.

\section{Diagnosis of depression}

A variety of depression scales were used to assess depression or the degree of depressive symptoms. These depression scales were either self-completed by patients (in
Fig. 1 Flow chart of study selection process

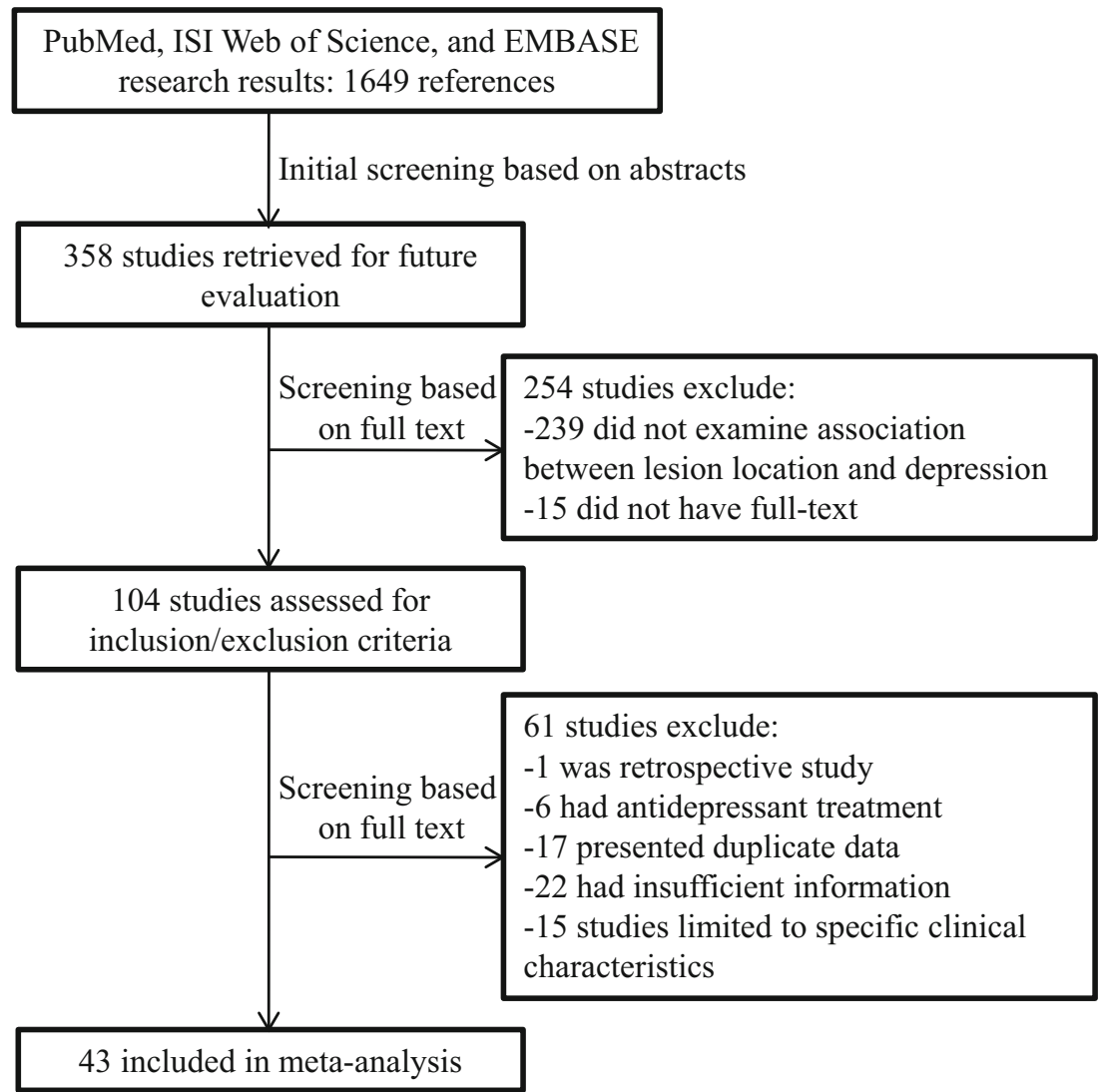


Table 1 Characteristics of eligible studies

\begin{tabular}{|c|c|c|c|c|c|c|c|c|c|}
\hline \multirow[t]{2}{*}{ Reference } & \multirow[t]{2}{*}{ Year } & \multirow[t]{2}{*}{ Country } & \multirow[t]{2}{*}{ Source of patients } & \multirow{2}{*}{$\begin{array}{l}\text { History } \\
\text { of } \\
\text { stroke } \\
\text { excluded }\end{array}$} & \multirow{2}{*}{$\begin{array}{l}\text { History of } \\
\text { depression } \\
\text { excluded }\end{array}$} & \multirow{2}{*}{$\begin{array}{l}\text { Severe } \\
\text { aphasia } \\
\text { excluded }\end{array}$} & \multicolumn{3}{|c|}{ Quality assessment by NOS } \\
\hline & & & & & & & Selection & Comparability & $\begin{array}{l}\text { Exposure/ } \\
\text { outcome }\end{array}$ \\
\hline Folstein et al. [17] & 1977 & USA & Rehabilitation & NG & $\mathrm{Y}$ & NG & $* * * *$ & $* *$ & $* * *$ \\
\hline Robinson et al. [7] & 1983 & USA & Clinic & $\mathrm{N}$ & NG & $\mathrm{Y}$ & $* * *$ & $* *$ & $* * *$ \\
\hline Eastwood et al. [18] & 1989 & Canada & Rehabilitation & $\mathrm{N}$ & $\mathrm{N}$ & $\mathrm{Y}$ & $* * *$ & $*$ & $* *$ \\
\hline Morris et al. [19] & 1990 & Britain & Clinic + rehabilitation & $\mathrm{N}$ & $\mathrm{N}$ & $\mathrm{N}$ & $* * *$ & $* *$ & $* *$ \\
\hline House et al. [20] & 1990 & Britain & Community & $\mathrm{Y}$ & $\mathrm{Y}$ & $\mathrm{Y}$ & $* * * *$ & $* *$ & $* *$ \\
\hline Sharpe et al. [21] & 1990 & Britain & Community & $\mathrm{Y}$ & $\mathrm{N}$ & $\mathrm{N}$ & $* * *$ & $* *$ & $* * *$ \\
\hline Starkstein et al. [22] & 1991 & USA & Clinic & NG & $\mathrm{N}$ & $\mathrm{N}$ & $* * *$ & $* *$ & $* * *$ \\
\hline Schwartz et al. [23] & 1993 & USA & Rehabilitation & NG & $\mathrm{N}$ & $\mathrm{Y}$ & $* * *$ & $*$ & $* * *$ \\
\hline Astrom et al. [24] & 1993 & Sweden & Clinic & $\mathrm{N}$ & $\mathrm{N}$ & NG & $* * *$ & $* *$ & $* *$ \\
\hline Loong et al. [25] & 1995 & Singapore & Rehabilitation & $\mathrm{Y}$ & $\mathrm{N}$ & $\mathrm{Y}$ & $* * *$ & $* *$ & $* *$ \\
\hline Gonzalez-Torrecillas et al. [26] & 1995 & Belgium & Rehabilitation & $\mathrm{N}$ & $\mathrm{N}$ & $\mathrm{Y}$ & $* * *$ & $* *$ & $* * *$ \\
\hline Andersen et al. [27] & 1995 & Denmark & Clinic & $\mathrm{Y}$ & $\mathrm{Y}$ & $\mathrm{Y}$ & $* * * *$ & $* *$ & $* *$ \\
\hline Herrmann et al. [28] & 1995 & Germany & Clinic & $\mathrm{Y}$ & $\mathrm{Y}$ & $\mathrm{N}$ & $* * *$ & $*$ & $* *$ \\
\hline Iacoboni et al. [29] & 1995 & Italy & Clinic & $\mathrm{Y}$ & $\mathrm{Y}$ & $\mathrm{Y}$ & $* * * *$ & $* *$ & $* * *$ \\
\hline Bjerg Bendsen et al. [30] & 1997 & Denmark & Rehabilitation & NG & $\mathrm{Y}$ & $\mathrm{Y}$ & $* * * *$ & $*$ & $* * *$ \\
\hline MacHale et al. [10] & 1998 & Britain & Clinic & $\mathrm{Y}$ & $\mathrm{Y}$ & $\mathrm{Y}$ & $* * * *$ & $*$ & $* *$ \\
\hline Pohjasvaara et al. [31] & 1998 & Finland & Clinic & NG & $\mathrm{N}$ & $\mathrm{Y}$ & $* * *$ & l & $* *$ \\
\hline Kase et al. [32] & 1998 & USA & Community & Y & $\mathrm{Y}$ & $\mathrm{N}$ & $* * * *$ & $* *$ & $* * *$ \\
\hline Paolucci et al. [33] & 1999 & Italy & Rehabilitation & $\mathrm{Y}$ & $\mathrm{Y}$ & $\mathrm{Y}$ & $* * * *$ & $* *$ & $* *$ \\
\hline Shimoda et al. [35] & 1999 & USA & Clinic & $\mathrm{Y}$ & $\mathrm{Y}$ & $\mathrm{N}$ & $* * * *$ & $* *$ & $* * *$ \\
\hline Singh et al. [36] & 2000 & Canada & Clinic & $\mathrm{N}$ & $\mathrm{N}$ & $\mathrm{Y}$ & $* * *$ & $*$ & $* *$ \\
\hline Gainotti et al. [34] & 2001 & Italy & Rehabilitation & $\mathrm{Y}$ & $\mathrm{Y}$ & NG & $* * *$ & $* *$ & $* *$ \\
\hline Berg et al. [37] & 2001 & Finland & Clinic & $\mathrm{Y}$ & $\mathrm{Y}$ & $\mathrm{Y}$ & $* * * *$ & $* *$ & $* * *$ \\
\hline Desmond et al. [38] & 2003 & USA & Clinic & $\mathrm{N}$ & $\mathrm{N}$ & $\mathrm{Y}$ & $* * *$ & $* *$ & $* *$ \\
\hline Hsieh and Kao [39] & 2005 & China & Clinic & $\mathrm{Y}$ & $\mathrm{Y}$ & $\mathrm{Y}$ & $* * * *$ & $* *$ & $* * *$ \\
\hline Spalletta et al. [40] & 2005 & Italy & Clinic & Y & $\mathrm{Y}$ & $\mathrm{Y}$ & $* * * *$ & l & $* *$ \\
\hline Nys et al. [41] & 2005 & Holand & Clinic & $\mathrm{Y}$ & $\mathrm{Y}$ & $\mathrm{Y}$ & $* * *$ & $* *$ & $* *$ \\
\hline Tang et al. [42] & 2005 & China & Clinic & $\mathrm{N}$ & $\mathrm{N}$ & $\mathrm{Y}$ & $* * *$ & $*$ & $* * *$ \\
\hline Glodzik-Sobanska et al. [43] & 2006 & Poland & Clinic & $\mathrm{Y}$ & $\mathrm{Y}$ & $\mathrm{Y}$ & $* * * *$ & $* *$ & $* *$ \\
\hline Caeiro et al. [44] & 2006 & Portugal & Clinic & $\mathrm{N}$ & $\mathrm{N}$ & $\mathrm{Y}$ & $* *$ & $* *$ & $* * *$ \\
\hline Brodaty et al. [45] & 2007 & Australia & Clinic & $\mathrm{N}$ & $\mathrm{N}$ & $\mathrm{Y}$ & $* * *$ & $* *$ & $* * *$ \\
\hline Provinciali et al. [46] & 2008 & Italy & Rehabilitation & $\mathrm{Y}$ & NG & $\mathrm{Y}$ & $* * *$ & $*$ & $* * *$ \\
\hline Oladiji et al. [47] & 2009 & Nigeria & Clinic & NG & $\mathrm{N}$ & $\mathrm{Y}$ & $* * *$ & $* *$ & $* * *$ \\
\hline Fuentes et al. [48] & 2009 & Spain & Clinic & $\mathrm{N}$ & $\mathrm{N}$ & $\mathrm{Y}$ & $* * *$ & $* *$ & $* * *$ \\
\hline Snaphaan et al. [49] & 2009 & Holand & Clinic & $\mathrm{N}$ & $\mathrm{N}$ & NG & $* * *$ & $* *$ & $* * *$ \\
\hline Nidhinandana et al. [50] & 2010 & Thailand & Clinic & NG & NG & $\mathrm{Y}$ & $* * *$ & $* *$ & $* *$ \\
\hline Nishiyama et al. [51] & 2010 & Japan & Clinic & $\mathrm{Y}$ & $\mathrm{Y}$ & $\mathrm{Y}$ & $* * * *$ & $*$ & $* *$ \\
\hline Bour et al. [52] & 2010 & Holand & Clinic & $\mathrm{Y}$ & $\mathrm{N}$ & $\mathrm{Y}$ & $* * *$ & $*$ & $* * *$ \\
\hline Tennen et al. [53] & 2011 & Canda & Clinic + rehabilitation & $\mathrm{Y}$ & $\mathrm{N}$ & $\mathrm{Y}$ & $* * *$ & $* *$ & $* *$ \\
\hline Altieri et al. [54]. & 2012 & Italy & Clinic & $\mathrm{N}$ & $\mathrm{Y}$ & $\mathrm{Y}$ & $* * * *$ & $* *$ & $* * *$ \\
\hline Choi-Kwon et al. [55] & 2012 & Korea & Clinic & $\mathrm{N}$ & $\mathrm{Y}$ & $\mathrm{Y}$ & $* * * *$ & l & $* * *$ \\
\hline Zhang et al. [56] & 2013 & China & Clinic & NG & $\mathrm{Y}$ & $\mathrm{Y}$ & $* * * *$ & $* *$ & $* *$ \\
\hline Rajashekaran et al. [57] & 2013 & India & Clinic & $\mathrm{Y}$ & NG & NG & $* * *$ & $* *$ & $* *$ \\
\hline
\end{tabular}

$Y$ yes, $N$ no, $N G$ not given

Asterisks indicate number of stars awarded for each item 
6 studies) or administered and scored by interviewers ( 37 studies), and the psychiatric interviews were conducted either alone (in 21 studies) or in combination with a selfadministered mood scale (16 studies). The cut-off points for the same scale used to assess depression across different studies were not consistent, such as multiple cutpoints were used for the Beck Depression Inventory (BDI) ( $\geq 10$ [37, 46, 52], $\geq 13$ [55]), Montgomery Assberg depression rating scale (MADS) $(\geq 6[31], \geq 7[36,44], \geq 8$ [41]) and the Hamilton depression rating scale (HAMD) for depression ( $\geq 7[56], \geq 8[48], \geq 10[39,45], \geq 13[27,43]$ ) and the HAMD for major depression ( $\geq 15$ [48], $\geq 17$ [39], $\geq 18$ [23, 27, 33]). Additionally, some studies did not describe the cut-off points to assess depression [7, 17, 18, 26, 30].

Risk effect of assessment

We firstly pooled all the studies to estimate the associations between stroke location and the prevalence of PSD. The studies $(n=43)$ involved 5,507 subjects: 2,743 with left hemisphere lesion and 2,764 with right hemisphere stroke. 898 cases of depression were detected from left hemisphere lesion sample and 918 from right hemisphere lesion sample. Significant heterogeneity was observed $\left(P_{\text {heterogeneity }}=\right.$ $0.00, I^{2}=55.9 \%$, Fig. 2 ), thus, we chose the randomeffects model to synthesize the data. The pooled OR with $95 \%$ CI for the association of stroke location and depression risk was $0.99(0.88-1.11)$ (Fig. 2). This result offered no support for the hypothesis that the risk of depression after stroke is affected by the location of the brain lesion.

Then, we did subgroups analyses according to the timing of interview for depression. Significant heterogeneity existed in acute post-stroke group $\left(n=18, P_{\text {heterogeneity }}=\right.$ $0.00, I^{2}=57.7 \%$, Fig. 3a), and subacute post-stroke group ( $n=22, P_{\text {heterogeneity }}=0.04, I^{2}=36.9 \%$, Fig. $3 \mathrm{~b}$ ). Thus, we chose the random-effects model to synthesize the data. The heterogeneity of chronic post-stroke group was low ( $n=6, P_{\text {heterogeneity }}=0.43, I^{2}=0.00 \%$, Fig. $3 \mathrm{c}$ ), so the fix-effects model was chose. A statistically significant association between right hemisphere stroke and PSD was found exclusively for studies with subacute post-stroke stroke phase $(\mathrm{OR}=0.79$, 95 \% CI 0.66-0.93, Fig. 3b). Overall results suggested people with right hemisphere stroke may be more susceptible to depression during
Fig. 2 The forest plots of OR with $95 \%$ CI for the overall association of stroke location and depression risk

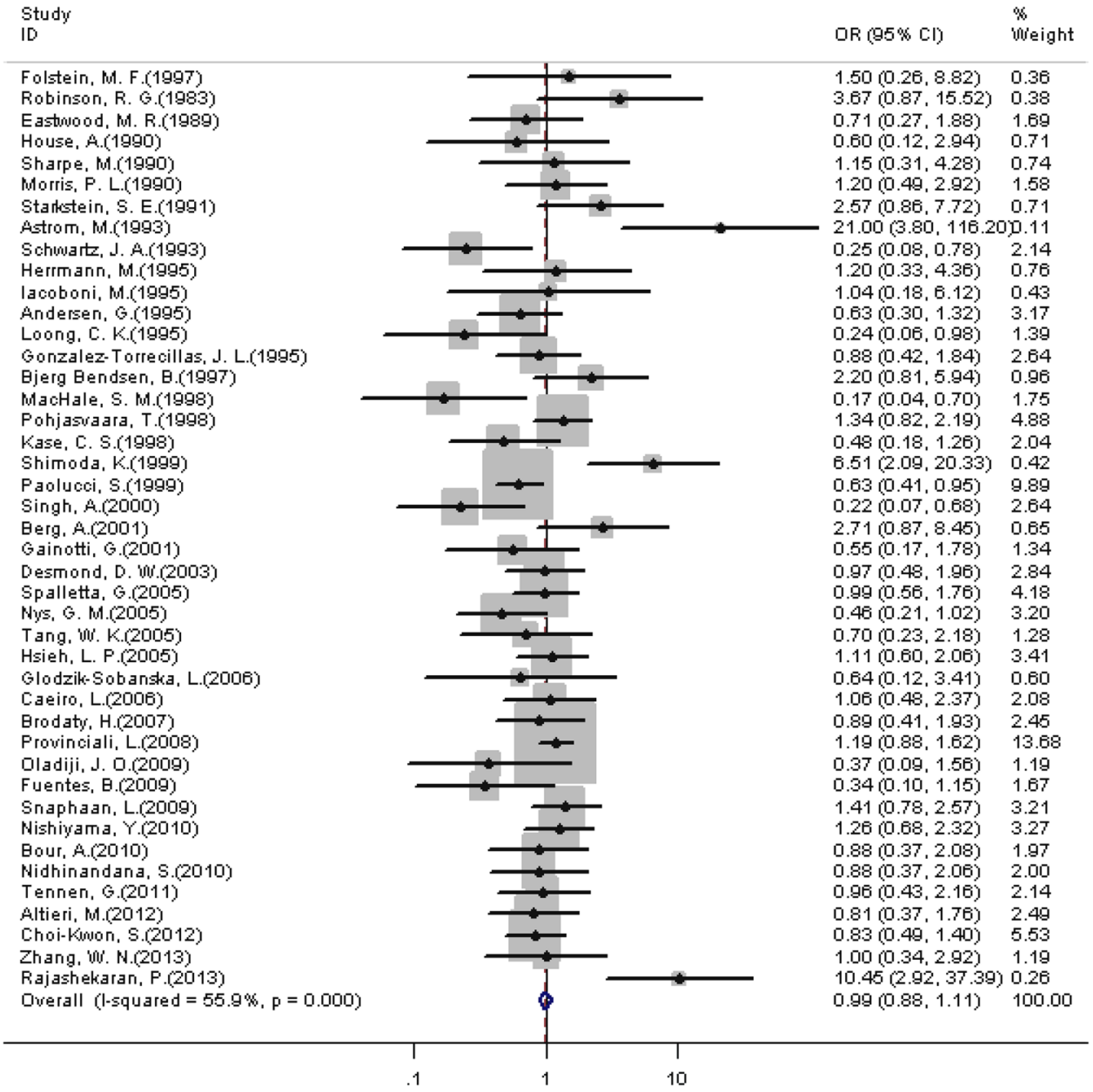


Fig. 3 The forest plots of OR with $95 \% \mathrm{CI}$ for the association of stroke location and depression risk according to time since stroke onset (a acute group, b subacute group, c chronic group)

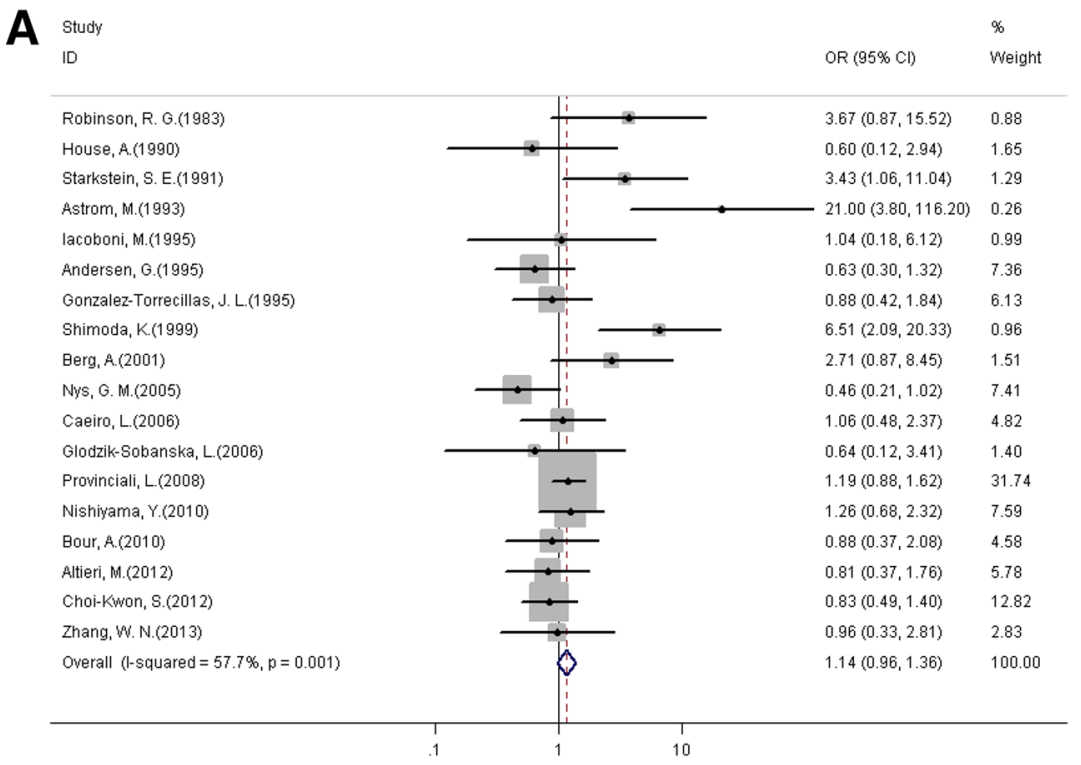

B

Study

OR $(95 \% \mathrm{Cl}) \quad$ Weight

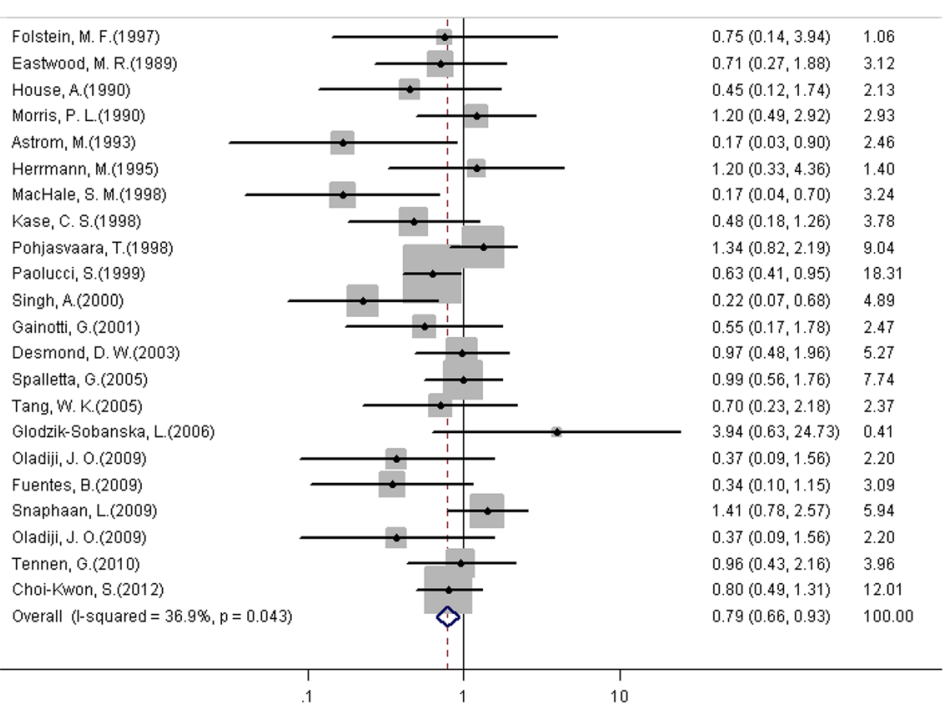

C Study

10

OR $(95 \% \mathrm{Cl}) \quad$ Weight

\begin{tabular}{|c|c|c|}
\hline House, A. (1990) & $0.19(0.02,1.83)$ & 13.04 \\
\hline Sharpe, M. (1990) & $1.15(0.31,4.28)$ & 13.13 \\
\hline Astrom, M.(1993) & $1.17(0.26,5.21)$ & 10.08 \\
\hline lacoboni, M.(1995) & $0.88(0.14,5.58)$ & 7.56 \\
\hline Nidhinandana, S. (2010) & $0.88(0.37,2.06)$ & 35.47 \\
\hline Overall (l-squared $=0.0 \%, p=0.434$ ) & $0.70(0.41,1.20)$ & 100.00 \\
\hline
\end{tabular}


subacute phase of stroke. We also did subgroup analyses according to the source of patients, but no significant difference was found (Table S1).

Quality assessment and sensitivity analyses

Quality assessment was shown in Table 1 and Table S2. We then conducted sensitive analyses to assess the influence of each study on the pooled OR. As shown in Table S3, when any single study was omitted, the corresponding ORs were not materially changed, suggesting high stability of this meta-analysis. For subgroup's sensitive analyses we also get the same conclusion (Table S4).

\section{Publication bias}

Begg's funnel plot and Egger's linear regression were performed to assess the publication bias of the included studies. The shapes of the funnel plots did not reveal any evidence of obvious asymmetry (Fig. 4). The results of Egger's test also showed that there were not statistically
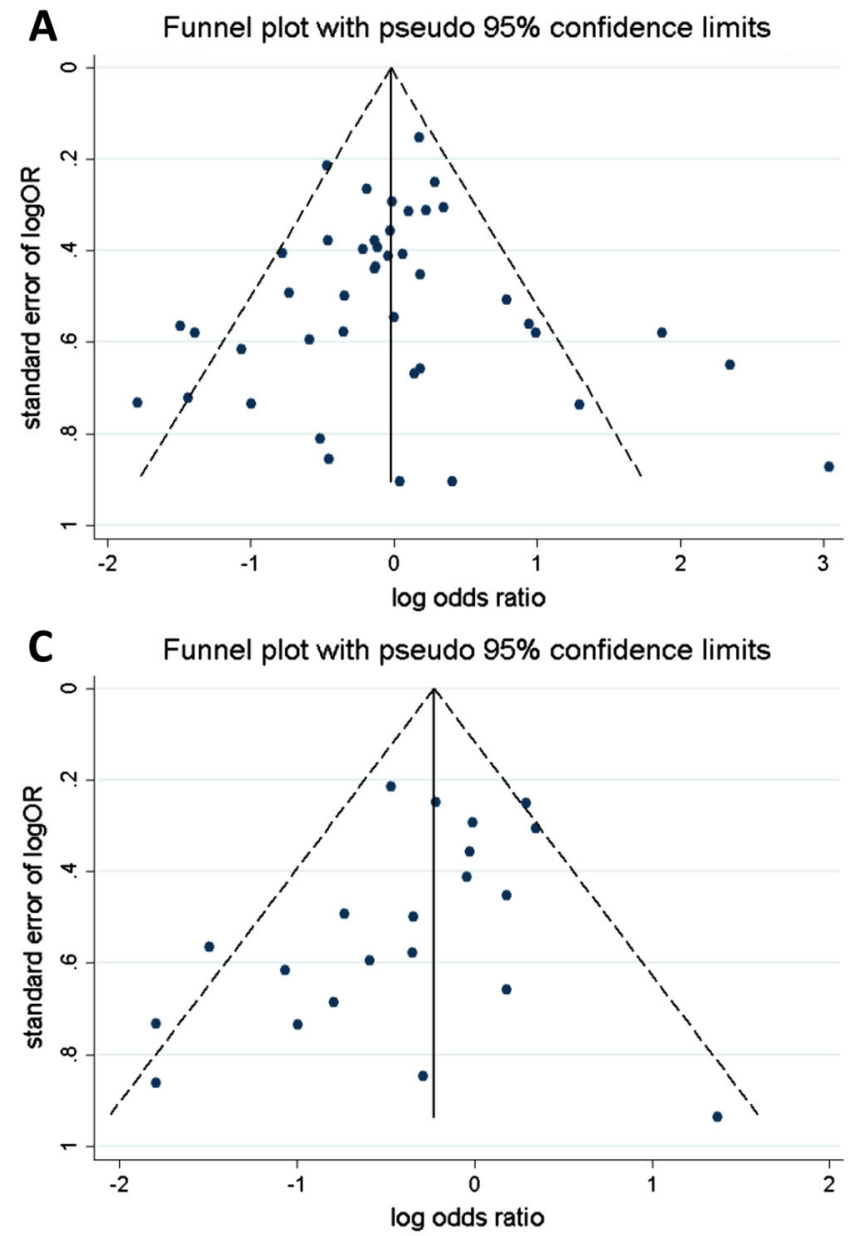

significant differences (total: $P_{\text {Egger's test }}=0.931$; acute group: $P_{\text {Egger's test }}=0.276$; subacute group: $P_{\text {Egger's test }}=$ 0.157; chronic group: $P_{\text {Egger's test }}=0.170$ ).

\section{Discussion}

PSD is thought to be a frequent complication of stroke associated with poorer outcomes. Available clinical data about the relationship between PSD and lesion location lacks strength and published results have been contradictory. Our meta-analysis revealed that there was a significant relationship between PSD and right hemisphere lesions when depression was assessed within 1-6 months after stroke.

Limitations of meta-analysis in this study

This study has several potential limitations. Firstly, the possibility of information and selection biases and unidentified confounders cannot be completely excluded because all of the included studies were observational.

B Funnel plot with pseudo $95 \%$ confidence limits

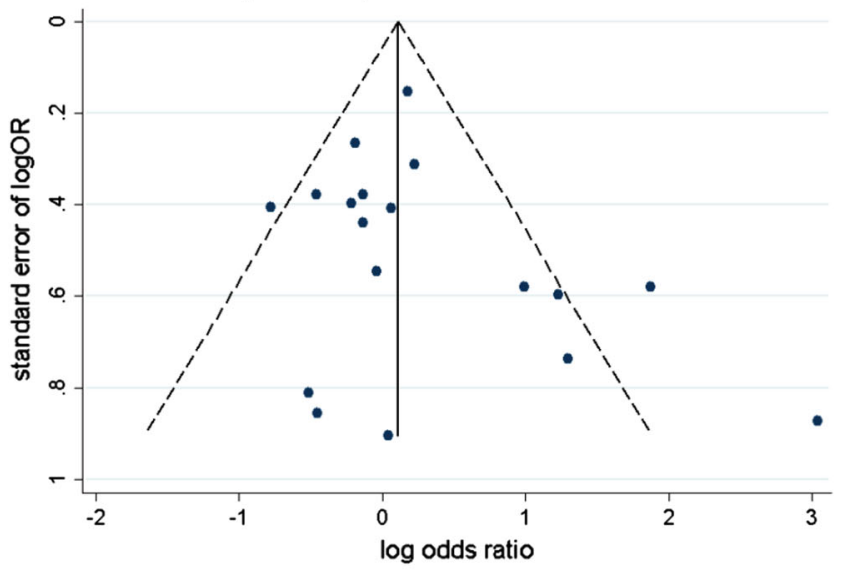

D Funnel plot with pseudo $95 \%$ confidence limits

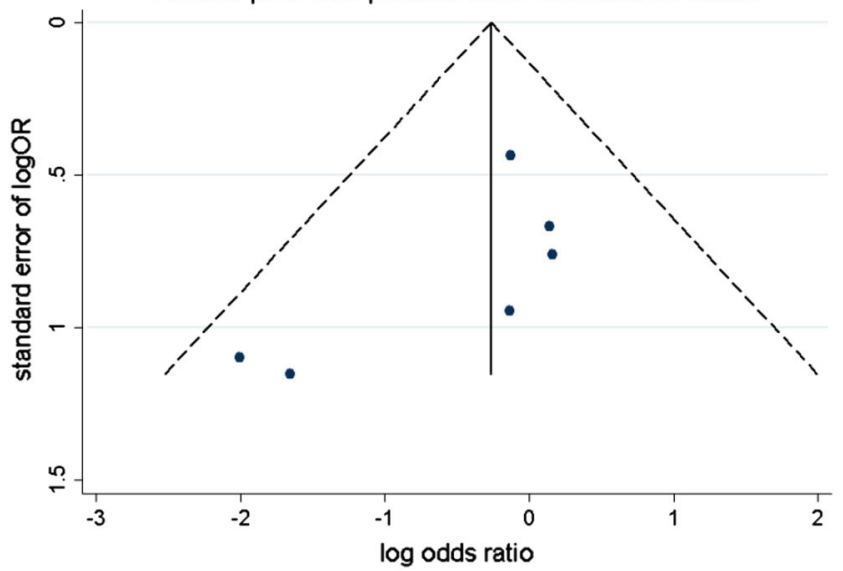

Fig. 4 Funnel blot was designed to visualize a potential publication bias (a overall studies, $\mathbf{b}$ acute group, $\mathbf{c}$ subacute group, $\mathbf{d}$ chronic group) 
Secondly, the time interval between stroke and depression assessment varied widely from several weeks to years. Thirdly, depression scales across different studies were various, even for the same scale the cut-off points used to assess degree of depressive symptoms were not consistent. Fourthly, studies used different methods of reporting results: some provided raw data from which OR could be calculated, while others provided either adjusted/unadjusted OR or other forms of statistical measures. This variability presented compatibility problems for analysis, and led to the inability to include certain studies in the analysis due to a lack of usable data. Lastly, we restricted our search strategy to articles published in English. Articles with potentially high-quality data that were published in other languages were not included because of anticipated difficulties in obtaining accurate medical translation.

Development of an appropriate and standardized measure of depression

The diagnosis of depression in stroke patients is a difficult task. The phenomenology of PSD is different from noncomorbid depression. Most instruments used to assess PSD were not originally developed for stroke populations therefore they have never been specifically validated in stroke patients. For example, as a direct consequence of stroke, patients may suffer from symptoms such as insomnia and loss of appetite, which may lead to an increase in false-positive depression scores. So it may get different conclusions for scales that include somatic items (e.g., BDI, HAMD) and others that seek to avoid such items [e.g., hospital anxiety and depression scale (HADS) and MADS]. Recent meta-analysis suggests that Center of Epidemiological Studies-Depression Scale (CES-D), HAMD or the Patient Health Questionnaire-9 (PHQ-9) as the most promising options to screen for PSD [58].

In most of the studies that we reviewed, many patients with severe aphasia were excluded from samples because patients with substantially impaired comprehension have difficulties completing most standardized interviews and scales. In fact, aphasia is a common consequence for patients with left hemispheric lesion. Consequently, the existence and severity of depression in patients with left hemisphere damage may be underestimated. To better research the relation between PSD and stroke location, evaluation methods for depression which are suitable for aphasic patients were needed.

Optimal time since stroke onset to assessment for PSD

Several studies have suggested that PSD over different terms may have different mechanisms, so the time interval between stroke onset and diagnosis of depression was an important confounder to confirm the association of PSD occurrence and stroke location. During the acute poststroke period ( $\leq 3$ months), depression has been associated with left anterior lesions, owing to a disruption in biogenic amine neurotransmission. However, during the post-acute period (3-6 months post-stroke), the proximity of the lesion to the frontal pole in both hemispheres influences the occurrence of post-stroke depression. For chronic stroke (1-2 years post-stroke), the occurrence of depression among survivors with left hemisphere lesions is mostly determined by severity of disability, whereas among those with right hemisphere damage, it is associated with lesion size and proximity to the occipital pole $[35,59]$. In Carson's study, no evidence supported the hypothesis that lesion location was associated with depression no matter when the depressive symptoms after stroke were assessed [11]. However, $\mathrm{Yu}$ et al. showed that depression was statistically associated with right hemisphere lesions when depression was assessed within 4-9 months after stroke. In our review, in the beginning we tried to group studies into acute post-stroke group ( $\leq 3$ months), subacute post-stroke group (3-6 months), and chronic post-stroke group ( $>6$ months) according to the biological mechanism as mentioned earlier, but no statistical association was found. Considering the average hospitalization time for most stroke patients was less than 1 month, then they would move back home or rehabilitation center to continue treatment, and authors of almost all of the studies that included in this review cut the time interval of follow-up into 1 month, 3 months, 6 months, 1 year or longer, we classify the subgroup into acute post-stroke group ( $\leq 1$ month), subacute post-stroke group (1-6 months), and chronic post-stroke group ( $>6$ months). Our conclusion showed risk of depression was associated with right hemisphere stroke when depression was assessed within 1-6 months after stroke.

Acknowledgments This work was supported by National Natural Science Foundation of China (81301165 to Jin H), Natural Science Fund of Hubei Province (2012FFB03706 to Jin H) and China Postdoctoral Science Foundation (2014M552047 to Jin H).

Conflicts of interest The authors declare that there is no conflict of interest.

\section{References}

1. Cully JA, Gfeller JD, Heise RA, Ross MJ, Teal CR, Kunik ME (2005) Geriatric depression, medical diagnosis, and functional recovery during acute rehabilitation. Arch Phys Med Rehabil $86: 2256-2260$

2. Gillen R, Tennen H, McKee TE, Gernert-Dott P, Affleck G (2001) Depressive symptoms and history of depression predict 
rehabilitation efficiency in stroke patients. Arch Phys Med Rehabil 82:1645-1649

3. Williams LS, Ghose SS, Swindle RW (2004) Depression and other mental health diagnoses increase mortality risk after ischemic stroke. Am J Psychiatry 161:1090-1095

4. Ayerbe L, Ayis S, Rudd AG, Heuschmann PU, Wolfe CD (2011) Natural history, predictors, and associations of depression 5 years after stroke: the South London Stroke Register. Stroke J Cereb Circ 42:1907-1911

5. Hackett ML, Yapa C, Parag V, Anderson CS (2005) Frequency of depression after stroke: a systematic review of observational studies. Stroke J Cereb Circ 36:1330-1340

6. Robinson RG, Shoemaker WJ, Schlumpf M, Valk T, Bloom FE (1975) Effect of experimental cerebral infarction in rat brain on catecholamines and behaviour. Nature 255:332-334

7. Robinson RG, Kubos KL, Starr LB, Rao K, Price TR (1983) Mood changes in stroke patients: relationship to lesion location. Compr Psychiatry 24:555-566

8. Robinson RG, Kubos KL, Starr LB, Rao K, Price TR (1984) Mood disorders in stroke patients. Importance of location of lesion. Brain J Neurol 107(Pt 1):81-93

9. Parikh RM, Lipsey JR, Robinson RG, Price TR (1987) Two-year longitudinal study of post-stroke mood disorders: dynamic changes in correlates of depression at one and two years. Stroke J Cereb Circ 18:579-584

10. MacHale SM, O'Rourke SJ, Wardlaw JM, Dennis MS (1998) Depression and its relation to lesion location after stroke. J Neurol Neurosurg Psychiatry 64:371-374

11. Carson AJ, MacHale S, Allen K, Lawrie SM, Dennis M, House A, Sharpe M (2000) Depression after stroke and lesion location: a systematic review. Lancet 356:122-126

12. Hadidi N, Treat-Jacobson DJ, Lindquist R (2009) Poststroke depression and functional outcome: a critical review of literature. Heart lung J Crit Care 38:151-162

13. Bhogal SK, Teasell R, Foley N, Speechley M (2004) Lesion location and poststroke depression: systematic review of the methodological limitations in the literature. Stroke J Cereb Circ 35:794-802

14. Yu L, Liu CK, Chen JW, Wang SY, Wu YH, Yu SH (2004) Relationship between post-stroke depression and lesion location: a meta-analysis. Kaohsiung J Med Sci 20:372-380

15. Begg CB, Mazumdar M (1994) Operating characteristics of a rank correlation test for publication bias. Biometrics 50:1088-1101

16. Egger M, Davey Smith G, Schneider M, Minder C (1997) Bias in meta-analysis detected by a simple, graphical test. BMJ 315:629-634 (clinical research ed)

17. Folstein MF, Maiberger R, McHugh PR (1977) Mood disorder as a specific complication of stroke. J Neurol Neurosurg Psychiatry 40:1018-1020

18. Eastwood MR, Rifat SL, Nobbs H, Ruderman J (1989) Mood disorder following cerebrovascular accident. Br J Psychiatry $\mathrm{J}$ Mental Sci 154:195-200

19. Morris PL, Robinson RG, Raphael B (1990) Prevalence and course of depressive disorders in hospitalized stroke patients. Int J Psychiatry Med 20:349-364

20. House A, Dennis M, Warlow C, Hawton K, Molyneux A (1990) Mood disorders after stroke and their relation to lesion location. A CT scan study. Brain J Neurol 113(Pt 4):1113-1129

21. Sharpe M, Hawton K, House A, Molyneux A, Sandercock P, Bamford J, Warlow C (1990) Mood disorders in long-term survivors of stroke: associations with brain lesion location and volume. Psychol Med 20:815-828

22. Starkstein SE, Bryer JB, Berthier ML, Cohen B, Price TR, Robinson RG (1991) Depression after stroke: the importance of cerebral hemisphere asymmetries. J Neuropsychiatry Clin Neurosci 3:276-285
23. Schwartz JA, Speed NM, Brunberg JA, Brewer TL, Brown M, Greden JF (1993) Depression in stroke rehabilitation. Biol Psychiatry 33:694-699

24. Astrom M, Adolfsson R, Asplund K (1993) Major depression in stroke patients. A 3-year longitudinal study. Stroke J Cereb Circ 24:976-982

25. Loong CK, Kenneth NK, Paulin ST (1995) Post-stroke depression: outcome following rehabilitation. Aust NZ J Psychiatry 29:609-614

26. Gonzalez-Torrecillas JL, Mendlewicz J, Lobo A (1995) Effects of early treatment of poststroke depression on neuropsychological rehabilitation. Int Psychogeriatr/IPA 7:547-560

27. Andersen G, Vestergaard K, Ingemann-Nielsen M, Lauritzen L (1995) Risk factors for post-stroke depression. Acta Psychiatr Scand 92:193-198

28. Herrmann M, Bartels C, Schumacher M, Wallesch CW (1995) Poststroke depression. Is there a pathoanatomic correlate for depression in the postacute stage of stroke? Stroke J Cereb Circ 26:850-856

29. Iacoboni M, Padovani A, Di Piero V, Lenzi GL (1995) Poststroke depression: relationships with morphological damage and cognition over time. Ital J Neurol Sci 16:209-216

30. Bjerg Bendsen B, Bjerg Bendsen E, Lauritzen L, Vilmar T, Bech $P$ (1997) Post-stroke patients in rehabilitation. The relationship between biological impairment (CT scanning), physical disability and clinical depression. Eur Psychiatry 12:399-404

31. Pohjasvaara T, Leppavuori A, Siira I, Vataja R, Kaste M, Erkinjuntti T (1998) Frequency and clinical determinants of poststroke depression. Stroke J Cereb Circ 29:2311-2317

32. Kase CS, Wolf PA, Kelly-Hayes M, Kannel WB, Beiser A, D'Agostino RB (1998) Intellectual decline after stroke: the Framingham Study. Stroke J Cereb Circ 29:805-812

33. Paolucci S, Antonucci G, Pratesi L, Traballesi M, Grasso MG, Lubich S (1999) Poststroke depression and its role in rehabilitation of inpatients. Arch Phys Med Rehabil 80:985-990

34. Gainotti G, Antonucci G, Marra C, Paolucci S (2001) Relation between depression after stroke, antidepressant therapy, and functional recovery. J Neurol Neurosurg Psychiatry 71:258-261

35. Shimoda K, Robinson RG (1999) The relationship between poststroke depression and lesion location in long-term follow-up. Biol Psychiatry 45:187-192

36. Singh A, Black SE, Herrmann N, Leibovitch FS, Ebert PL, Lawrence J, Szalai JP (2000) Functional and neuroanatomic correlations in poststroke depression: the Sunnybrook Stroke Study. Stroke J Cereb Circ 31:637-644

37. Berg A, Palomaki H, Lehtihalmes M, Lonnqvist J, Kaste M (2001) Poststroke depression in acute phase after stroke. Cerebrovasc Dis 12:14-20

38. Desmond DW, Remien RH, Moroney JT, Stern Y, Sano M, Williams JB (2003) Ischemic stroke and depression. J Int Neuropsychol Soc JINS 9:429-439

39. Hsieh LP, Kao HJ (2005) Depressive symptoms following ischemic stroke: a study of 207 patients. Acta Neurol Taiwanica 14:187-190

40. Spalletta G, Ripa A, Caltagirone C (2005) Symptom profile of DSM-IV major and minor depressive disorders in first-ever stroke patients. Am J Geriatr Psychiatry Off J Am Assoc Geriatr Psychiatry 13:108-115

41. Nys GM, van Zandvoort MJ, van der Worp HB, de Haan EH, de Kort PL, Kappelle LJ (2005) Early depressive symptoms after stroke: neuropsychological correlates and lesion characteristics. J Neurol Sci 228:27-33

42. Tang WK, Chan SS, Chiu HF, Ungvari GS, Wong KS, Kwok TC, Mok V, Wong KT, Richards PS, Ahuja AT (2005) Poststroke depression in Chinese patients: frequency, psychosocial, clinical, and radiological determinants. J Geriatr Psychiatry Neurol 18:45-51 
43. Glodzik-Sobanska L, Slowik A, McHugh P, Sobiecka B, Kozub J, Rich KE, Urbanik A, Szczudlik A (2006) Single voxel proton magnetic resonance spectroscopy in post-stroke depression. Psychiatry Res Neuroimaging 148:111-120

44. Caeiro L, Ferro JM, Santos CO, Figueira ML (2006) Depression in acute stroke. J Psychiatry Neurosci JPN 31:377-383

45. Brodaty H, Withall A, Altendorf A, Sachdev PS (2007) Rates of depression at 3 and 15 months post stroke and their relationship with cognitive decline: the Sydney Stroke Study. Am J Geriatr Psychiatry 15:477-486

46. Provinciali L, Paolucci S, Torta R, Toso V, Gobbi B, Gandolfo C (2008) Depression after first-ever ischemic stroke: the prognostic role of neuroanatomic subtypes in clinical practice. Cerebrovasc Dis 26:592-599

47. Oladiji JO, Akinbo SR, Aina OF, Aiyejusunle CB (2009) Risk factors of post-stroke depression among stroke survivors in Lagos, Nigeria. Afr J Psychiatry 12:47-51

48. Fuentes B, Ortiz X, Sanjose B, Frank A, Diez-Tejedor E (2009) Post-stroke depression: can we predict its development from the acute stroke phase? Acta Neurol Scand 120:150-156

49. Snaphaan L, van der Werf S, Kanselaar K, de Leeuw FE (2009) Post-stroke depressive symptoms are associated with post-stroke characteristics. Cerebrovasc Dis 28:551-557

50. Nidhinandana S, Sithinamsuwan P, Chinvarun Y, Wongmek W, Supakasem S, Suwantamee J (2010) Prevalence of poststroke depression in Thai stroke survivors studied in Phramongkutklao Hospital. J Med Assoc Thail Chotmaihet Thangphaet 93(Suppl 6):S60-S64

51. Nishiyama Y, Komaba Y, Ueda M, Nagayama H, Amemiya S, Katayama Y (2010) Early depressive symptoms after ischemic stroke are associated with a left lenticulocapsular area lesion. J Stroke Cerebrovasc Dis Off J Natl Stroke Assoc 19:184-189
52. Bour A, Rasquin S, Aben I, Boreas A, Limburg M, Verhey F (2010) A one-year follow-up study into the course of depression after stroke. J Nutr Health Aging 14:488-493

53. Tennen G, Herrmann N, Black SE, Levy KS, Cappell J, Li A, Lanctot KL (2011) Are vascular risk factors associated with poststroke depressive symptoms? J Geriatr Psychiatry Neurol 24:215-221

54. Altieri M, Maestrini I, Mercurio A, Troisi P, Sgarlata E, Rea V, Di Piero V, Lenzi GL (2012) Depression after minor stroke: prevalence and predictors. Eur J Neurol Off J Eur Fed Neurol Soc 19:517-521

55. Choi-Kwon S, Han K, Choi S, Suh M, Kim YJ, Song H, Cho KH, Nah HW, Kwon SU, Kang DW, Kim JS (2012) Poststroke depression and emotional incontinence: factors related to acute and subacute stages. Neurology 78:1130-1137

56. Zhang WN, Pan YH, Wang XY, Zhao Y (2013) A prospective study of the incidence and correlated factors of post-stroke depression in China. PLoS One 8:e78981

57. Rajashekaran P, Pai K, Thunga R, Unnikrishnan B (2013) Poststroke depression and lesion location: a hospital based crosssectional study. Indian J Psychiatry 55:343-348

58. Meader N, Moe-Byrne T, Llewellyn A, Mitchell AJ (2014) Screening for poststroke major depression: a meta-analysis of diagnostic validity studies. J Neurol Neurosurg Psychiatry 85:198-206

59. Santos M, Kovari E, Gold G, Bozikas VP, Hof PR, Bouras C, Giannakopoulos P (2009) The neuroanatomical model of poststroke depression: towards a change of focus? J Neurol Sci 283:158-162 